\title{
The coping strategies used over a two-year period by HIV-positive women who had been diagnosed during pregnancy
}

\author{
Marinda Kotze ${ }^{\mathrm{a}, \mathrm{b} *}$, Maretha Visser ${ }^{\mathrm{a}}$, Jennifer Makin ${ }^{\mathrm{c}}$, Kathy Sikkema $^{\mathrm{d}}$ and Brian Forsyth ${ }^{\mathrm{e}}$ \\ ${ }^{a}$ Department of Psychology, University of Pretoria, Pretoria, South Africa; \\ ${ }^{\mathrm{b}}$ MRC-UNISA Safety andPeace Promotion Research Unit, Tygerberg, South Africa; \\ ${ }^{c}$ Medical Research Unit for Maternal and Infant Health Care Strategies, Pretoria, South Africa; \\ ${ }^{\mathrm{d}}$ Department of Psychology and Neuroscience andDuke Global Health Institute, Duke University, Durham, NC, USA; \\ ${ }^{\mathrm{e}}$ Centre of Interdisciplinary Research on AIDS, Yale University, New Haven, CT, USA
}

\begin{abstract}
Structured interviews were conducted with 224 HIV-positive women diagnosed during pregnancy, at antenatal clinics in Tshwane, South Africa, in order to investigate the use of coping strategies during the first two years after diagnosis. Interview s were conducted between one and four weeks after diagnosis during pregnancy, with three follow-up interviews conducted post-partum. Coping strategies were assessed with an adapted version of the Brief COPE. It was found that active coping was used more often than avoidant coping throughout the study period. Active coping increased over time, while avoidant coping decreased at first but increased again between 6 and 21 months after diagnosis. The most frequently used coping strategies included acceptance, direct action, positive reframing, religion and distraction. At first, women coped through internalised strategies. Over time, outward-focused strategies developed. Avoidant coping patterns differed from previous research indicating that women diagnosed during pregnancy deal with the consequences of HIV after the baby is born. Recommendations for mental health services are made.
\end{abstract}

Keywords: coping; HIV-positive women; longitudinal; pregnancy; quantitative; South Africa

Lazarus and Folkman (1984) define coping as "constantly changing cognitive and behavioural efforts to manage specific external and/or internal demands that are appraised as taxing or exceeding the resources of the person" (p. 141). Coping is a dynamic process that changes in response to the relationship between the person and the stressful environment (Lazarus \& Folkman, 1984). Consequently, efforts to cope with illness can be expected to change over time. Limited research has been conducted on coping strategies of people living with HIV and the research that has been done has generated conflicting conclusions.

From the point of diagnosis onwards, HIVinfected people experience varying emotional reactions and employ various coping strategies (Chida \& Vedhara, 2009). However, it is still uncertain whether there is a specific coping pattern over time, similar to Kubler-Ross's (1969) stages of adjustment to a terminal illness. It has been suggested that changes in coping over time are linked to several variables such as disease progression, presence of AIDS-related symptoms, changing levels of psychological distress and prior use of coping strategies (Chida \& Vedhara, 2009; Fleishman et al., 2003).

*Corresponding author. Email: marinda.kotze1@gmail.com
In a qualitative study involving 18 people living with HIV, Reeves, Merriam and Courtenay (1999) identified three stages of coping during the first 18 months after diagnosis. During the first stage, immediately after diagnosis, some participants coped with intense emotional experiences through avoidance, by continuing their lives as if nothing had happened. Others actively searched for information to prepare for their future. The second stage is called the transition phase, during which participants tried to regain control and purposefully confront their situation. This assisted them to accept their HIV status during the third stage. None of these stages can be associated with a specific time frame. Reeves et al. (1999) observed a gradual shift across the three phases from reactive coping to increasingly proactive coping and taking control.

These stages were not found in research using quantitative data (Leiberich et al., 1997; Olley, 2006). Leiberich et al. (1997) found that goal-oriented action coping was the most frequently used coping strategy a few months after diagnosis, followed by problem analysis, seeking social support and passive acceptance. At 18-month follow-up, the coping strategies used remained similar, although some movement was 
observed towards more active and meaning making coping and less avoidant coping strategies.

A few studies explored coping in newly diagnosed people in South Africa (Myint \& Mash, 2008; Olley, 2006; Olley, Seedat, \& Stein, 2006). Myint and Mash (2008) found emotional support, acceptance, positive reframing, religion, active coping and planning as the most frequently used coping strategies two weeks after diagnosis. Negative coping strategies such as disengagement, venting emotions and denial were the least frequently used. Olley et al. (2006) identified similar coping strategies at baseline (about one year after diagnosis). From baseline to six months followup, Olley (2006) found that negative coping strategies such as denial, self-blame, behavioural disengagement and venting of emotions decreased significantly, whereas positive coping strategies increased significantly. No significant differences were found between coping of HIV-positive men and women (Olley et al., 2006).

Previous research thus suggests that coping with HIV is a dynamic process and that different coping strategies are used over time. Limited research has been conducted on the coping strategies of women diagnosed during pregnancy and on how they cope subsequent to giving birth. Additionally, limited longitudinal research has been conducted on the use of coping strategies over time, particularly from diagnosis onwards.

\section{Methodology}

A longitudinal research design was used to study the coping strategies used by HIV-positive women diagnosed during pregnancy, during the first two years after diagnosis and to explore whether there is a specific coping pattern over time.

\section{Sample}

HIV counsellors at four antenatal clinics in Tshwane (South Africa) recruited newly diagnosed HIVpositive pregnant women who were entered into the PMTCT programme, for the study. Of these newly diagnosed women, 438 were invited and 293 agreed to participate in the study $(67 \%)$. The inclusion criterion for participation in the study was that the pregnant women had to have been diagnosed with HIV for the first time during the current pregnancy. Exclusion criteria for recruitment included being younger than 15 years old at time of recruitment, testing HIVpositive prior to the current pregnancy and likelihood that the woman would move away from Tshwane during the two-year study period.

\section{Data collection}

Data were collected by means of four structured interviews. The baseline interview was held between one and four weeks after diagnosis, when the women were approximately 28 weeks pregnant (Table 1). Most women were in the second trimester of pregnancy although some variations occurred. Follow-up interviews were scheduled at times of the women's routine clinic visits for immunisation of their infants. These interviews were conducted at approximately 6 , 12 and 21 months after the baseline interview (3, 9 and 18 months after the infants' birth). Because the baseline interview varied by trimester for some women, the period of baseline to the first follow-up (six months interview) may differ somewhat. The data collection phase spanned approximately two years. Besides the assessments, no other interventions were implemented.

\section{Measurement instruments}

Questions on demographic variables were posed, including age, marital status, education level, employment status, monthly household income and whether they were using antiretroviral treatment (ART). An adapted version of the Brief COPE was used to measure the use of coping strategies. The Brief COPE (Carver, 1997) consists of 14 coping scales

Table 1. Socio-demographics and health-related characteristics at baseline $(N=224)$.

\begin{tabular}{lr}
\hline Age [mean(sd)] & $26.5(5.1)$ years \\
Gestational age [mean (sd)] & $27.6(7.0)$ \\
Marital status $N(\%)$ & \\
$\quad$ Married & $43(19.1)$ \\
Single with partner & $152(67.9)$ \\
$\quad$ No partner & $29(12.9)$ \\
Education level $N(\%)$ & $21(9.3)$ \\
$\quad$ None/primary & $171(76.3)$ \\
$\quad$ Some form of secondary & $32(14.3)$ \\
Some form of tertiary & \\
Household income monthly per-capita & R20 $(U S \$ 40)$ \\
[median] & \\
Regular income employment $N(\%)$ & $52(23.2)$ \\
Participant & $151(67.4)$ \\
Partner & \\
Interval since HIV test done $N(\%)$ & $63(28.1)$ \\
$\quad<1$ week & $94(42.0)$ \\
$1-4$ weeks & $67(29.9)$ \\
$>4$ weeks & $433(232.5)$ \\
CD4 [mean (sd)] & $27(12.2)$ \\
$\quad<200 N(\%)$ at 12 months follow-up & $19(10.6)$ \\
Using ART at 12 months follow-up & \\
\hline
\end{tabular}

Note: $N$, Number; sd, standard deviation. 
and 28 items. The adapted version consists of 15 scales and 28 items. The 'humour' scale was removed and two scales 'escape' and 'helping others' were included. Previous research (Pittiglio \& Hough, 2009; Skinner, Edge, Altman, \& Sherwood, 2003) showed that people living with HIV often cope by reaching out to others in an effort to find meaning. Some items of the original scale were rephrased to focus specifically on HIV.

Participants were asked to indicate how often they used a particular coping strategy: "most of the time" (scored as two), "some of the time" (scored as one) and "almost never" (scored as zero). A score was obtained for each coping strategy by adding the scores of the two corresponding items. There were two coping strategies "substance use" and "selfblame" that were measured by only one item each. In order to have comparable scores on all the scales, the scores of those items were doubled. Consequently, each coping scale is scored out of four.

In an exploratory factor analysis Makin et al. (2008) identified two factors (coping styles), namely, active and avoidant coping. Active coping strategies included acceptance, direct action, religion, positive reframing, emotional and instrumental support, information seeking and helping others. Avoidant coping included seven coping strategies, namely, distraction, denial, escape, emotional venting, out-of-control, self-blame and substance use. The Cronbach reliability coefficient of the scale as a whole was 0.63 for this sample; 0.75 for active and a lower 0.54 for avoidant coping.

\section{Data analysis}

A descriptive analysis of the data was used to report the frequency of use of coping strategies at each assessment period. T-tests were conducted to compare coping strategies used in different assessment periods.

\section{Ethical clearance}

The study was ethically approved by the Faculty of Health Sciences Research Ethics Committee of the University of Pretoria (Protocol number 209a) and the Human Investigation Committee of the Yale University School of Medicine.

\section{Results}

\section{Interview attendance}

A total of 293 newly diagnosed HIV-positive pregnant women agreed to take part in the baseline interview. Of these, 224 participated in one or more follow-up interviews and were included in the analysis. Despite slight demographic differences, there were no significant differences found between the coping strategies used by the 69 women who did not take part in any follow-up interviews and the initial coping strategies of the 224 women who continued participating in the research. Of the 224 women who were retained from the baseline interview, 198 women $(68 \%)$ participated in the 6-month follow-up interview, $175(60 \%)$ women in the 12-month follow-up and 166 women $(57 \%)$ in the 21-month follow-up interview.

\section{Socio-demographic characteristics}

Table 1 presents the socio-demographic characteristics of the women as recorded at the baseline interview. The mean age of the women was 26.5 years. Most of them were from low socio-economic status. The largest group $(76.3 \%)$ had some secondary education, $23.2 \%$ had a regular income and reported a median monthly household income per capita of R320 (approximately US\$40). Most of the women had been diagnosed with HIV between one and four weeks prior to the baseline interview $(70 \%)$. At the 12 -month interview, $10.6 \%$ of the women indicated that they recently started on antiretroviral treatment (ART) because of low CD4 count $(<200)$.

\section{Use of coping strategies at baseline}

Figure 1 illustrates the use of coping strategies at baseline. Acceptance was the most frequently reported coping strategy, followed by positive reframing, direct action and religion (forms of active coping) and distraction (a form of avoidant coping). Thus, shortly after diagnosis during pregnancy, the women more frequently used active coping strategies. Specifically, they used internalised strategies (acceptance, positive reframing and religion) more often, whereas outward-focused coping strategies (including seeking information, emotional and instrumental support and helping others) were used less often. Avoidant coping strategies were used less often. Distraction and escape were the most frequently used avoidant coping strategies with denial, emotional venting and selfblame being used less frequently. Substance use was rarely reported.

\section{Use of coping strategies at follow-up interviews}

Table 2 indicates the mean scores (0-4) of active and avoidant coping strategies used at all the four assessment periods. Acceptance, direct action, religion, positive reframing and distraction remained 
Active Coping Avoidant Coping

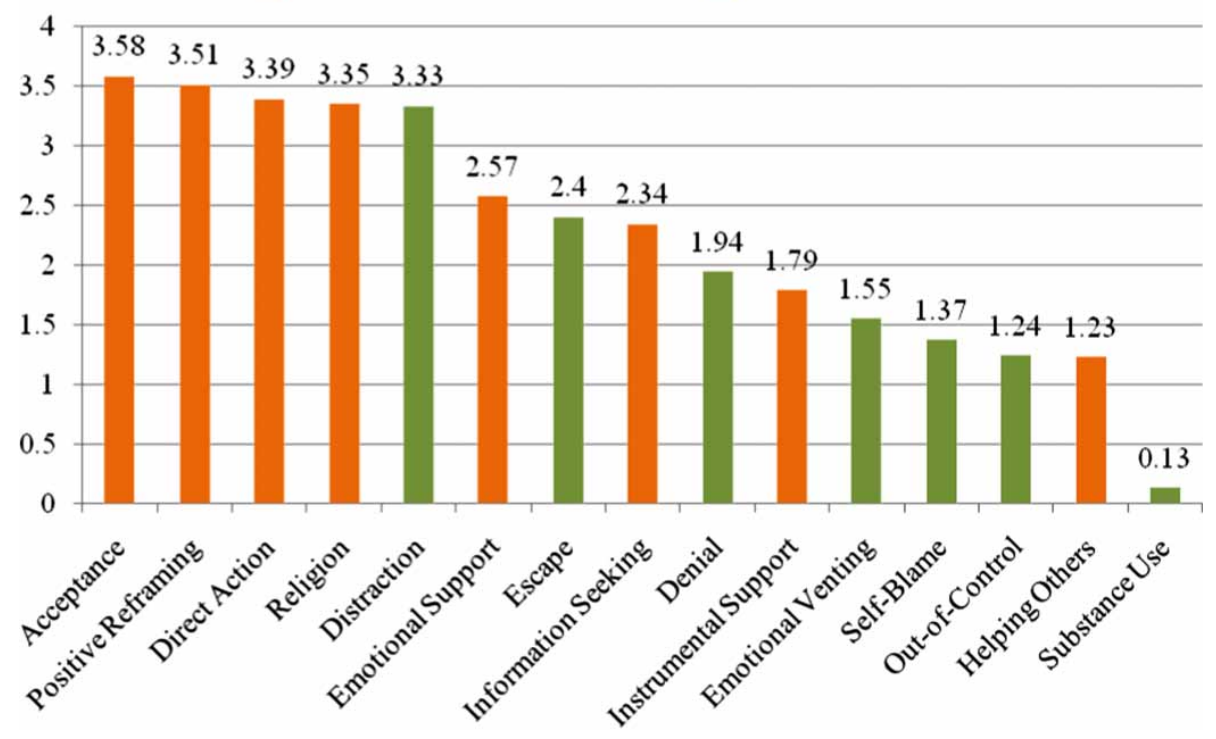

Figure 1. Coping strategy use at baseline.

the most frequently reported coping strategies over all the assessment periods. Similarly, substance use remained the least frequently reported coping

Table 2. Coping strategy use at baseline, 6, 12 and 21 months follow-up.

\begin{tabular}{|c|c|c|c|c|}
\hline Coping strategy & $\begin{array}{l}\text { Baseline } \\
(n=224)\end{array}$ & $\begin{array}{c}6 \\
\text { months } \\
(n=198)\end{array}$ & $\begin{array}{c}12 \\
\text { months } \\
(n=175)\end{array}$ & $\begin{array}{c}21 \\
\text { months } \\
(n=166)\end{array}$ \\
\hline \multicolumn{5}{|l|}{ Active coping } \\
\hline Acceptance & 3.58 & $3.8^{*}$ & 3.82 & 3.71 \\
\hline $\begin{array}{l}\text { Positive } \\
\text { reframing }\end{array}$ & 3.51 & 3.54 & 3.63 & 3.52 \\
\hline Direct action & 3.39 & $3.69 *$ & 3.77 & 3.7 \\
\hline Religion & 3.35 & $3.7 *$ & 3.64 & 3.58 \\
\hline $\begin{array}{c}\text { Emotional } \\
\text { support }\end{array}$ & 2.57 & 2.76 & 2.68 & 2.76 \\
\hline $\begin{array}{l}\text { Information } \\
\text { seeking }\end{array}$ & 2.34 & $2.52 *$ & 2.59 & 2.71 \\
\hline $\begin{array}{l}\text { Instrumental } \\
\text { support }\end{array}$ & 1.79 & $2.11^{*}$ & 2.18 & 2.29 \\
\hline Helping others & 1.23 & $1.7^{*}$ & $2.21 *$ & 2.25 \\
\hline \multicolumn{5}{|l|}{ Avoidant coping } \\
\hline Distraction & 3.33 & 3.24 & 3.26 & 3.29 \\
\hline Escape & 2.40 & 2.27 & 2.25 & 2.45 \\
\hline Denial & 1.94 & 1.99 & 1.99 & $2.42 *$ \\
\hline $\begin{array}{c}\text { Emotional } \\
\text { venting }\end{array}$ & 1.55 & 1.62 & 1.61 & $1.78 *$ \\
\hline Self-blame & 1.37 & $1.23 *$ & $1.08 *$ & $0.2^{*}$ \\
\hline Out of control & 1.24 & $0.98 *$ & 0.96 & $0.7^{*}$ \\
\hline Substance use & 0.13 & 0.06 & 0.09 & 0.27 \\
\hline
\end{tabular}

Note: *Significant difference compared to previous assessment $(p<0.05$, two-tailed). strategy from baseline to 12 months follow-up, after which self-blame became the least used coping strategy. The coping pattern thus remained relatively stable over the two-year study period.

Figure 2 illustrates active coping strategy usage over the study period. From baseline to six months follow-up, six of the eight active coping strategies increased significantly. These coping strategies include direct action $[t(196)=3.89, r=0.3]$, helping others $[t(196)=3.72, r=0.3]$, acceptance $[t(195)=$ $3.50, r=0.2]$, religion $[t(195)=3.45, r=0.2]$, instrumental support $[t(196)=2.42, r=0.2]$ and information seeking $[t(196)=1.68, r=0.1]$.

The most marked change over the study period was observed in helping others, which increased significantly during the first six months as well as from 6 to 12 months $[t(158)=4.89, r=0.4]$ before levelling off. Outward-focused coping strategies thus increased with time.

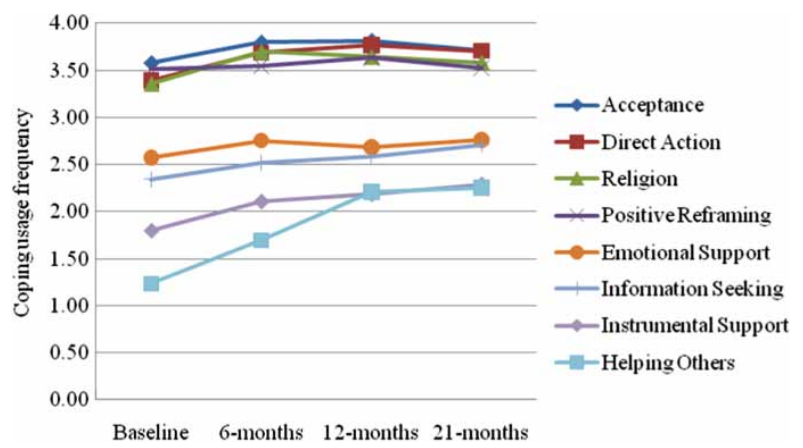

Figure 2. Use of active coping strategies over time. 
There was less change in avoidant coping scores over time (Figure 3), except out-of-control and selfblame which decreased significantly throughout the study period, particularly from 12 to 21 months (out-of-control $[t(144)=-2.04, \quad r=0.2]$; self-blame $[t(143)=-17.89, r=0.8])$. In contrast, denial $[t(144)=$ $3.41, r=0.3]$ and emotional venting $[t(144)=2.34, r=$ 0.2 ] increased significantly between 12 and 21 months.

Table 3 presents the means scores for active and avoidant coping styles over time. Active coping tended to increase, with scores at all follow-up periods being significantly higher at baseline $(p<$ 0.001). Avoidant coping scores dropped slightly at the six-month follow-up and then significantly increased between 6 and 21 months $(p<0.01)$.

\section{Discussion}

Newly diagnosed HIV-positive pregnant women are more likely to cope in an active way directly after diagnosis. They mostly accept their status, take direct action, turn to religion, positively reframe their situations and occasionally seek ways to distract themselves in order to cope. In contrast with previous research conducted with HIV-positive women in South Africa that found a gradual shift from avoidant to active coping over time (Olley, 2006; Olley et al., 2006), this study with pregnant HIV-positive women found that active coping was used more frequently from diagnosis onwards. There is a gradual increase in both active and avoidant coping over time, though avoidant coping decreases slightly shortly after diagnosis, but increases again after the women have known their status for about six months.

Over the study period, the pattern of coping remained relatively stable. During the first six months after diagnosis (before the infant turned three months) there were some significant increases in the use of active coping. While inward-focused coping strategies (e.g. acceptance and positive reframing)

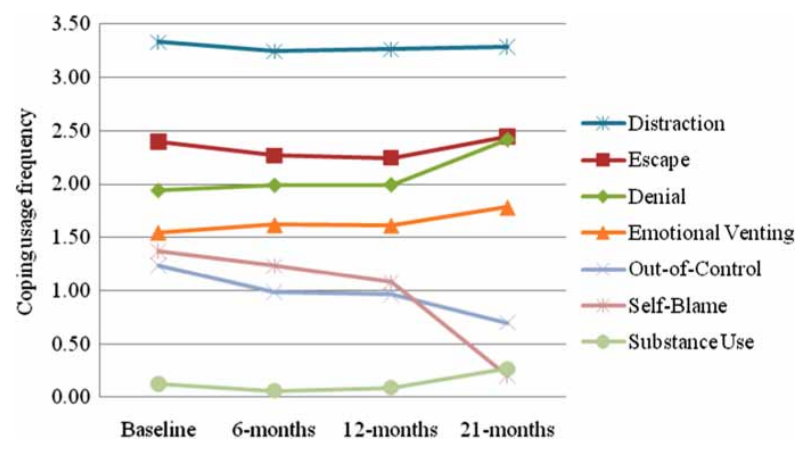

Figure 3. Use of avoidant coping strategies over time.
Table 3. Mean scores for active and avoidant coping at each interview.

\begin{tabular}{lccccc}
\hline & \multicolumn{2}{c}{ Active coping } & & \multicolumn{2}{c}{ Avoidant coping } \\
\cline { 2 - 3 } \cline { 6 - 6 } Interview time & Mean & Std. Error & & Mean & Std. Error \\
\hline Baseline & 32.492 & 0.372 & & 14.188 & 0.181 \\
6 months & 33.164 & 0.388 & & 13.874 & 0.186 \\
12 months & 33.803 & 0.338 & & 14.056 & 0.191 \\
21 months & 33.565 & 0.336 & & 14.575 & 0.172 \\
\hline
\end{tabular}

were used more at first, outward-focused coping strategies (e.g. information seeking, seeking instrumental support and helping others) increased from baseline onwards. After six months, changes were observed only with regard to feeling out-of-control and self-blame (avoidant coping which decreased) and helping others (active coping which increased). These findings suggest that the first six months after diagnosis may be a critical stage in the coping process. During this time, women implement a number of changes in order to come to terms with their diagnosis.

Previous research suggests that acceptance immediately after diagnosis is often passive acceptance of an uncontrollable situation (Skinner et al., 2003). The pregnancy and the perceived implications of HIV for the infant may have resulted in quick acceptance to take active steps to improve their health. The women's frequent use of religion as coping strategy suggests that spirituality remains an essential source of strength and meaning for recently diagnosed women (Griswold, Evans, Spielman, \& Fishman, 2005; Myint \& Mash, 2008; Trevino et al., 2007).

Similar to previous research (Blaney et al., 2004; Olley, 2006; Sanders, 2008) social support is identified as an important coping strategy. This research shows that women increasingly sought support and information between baseline and six months follow-up (outward-focused coping strategies). Helping others increased substantially throughout the study period. Previous research suggests that, as time progressed and people accept their diagnosis, they develop a desire to support others living with HIV or to protect the non-infected in an effort to find meaning (Pittiglio \& Hough, 2009; Reeves et al., 1999).

Similar to other research (Myint \& Mash, 2008; Olley, 2006) avoidant coping strategies were used less often throughout the research period. In contrast to previous research, a different pattern of avoidant coping emerged among recently diagnosed pregnant women. After a slight initial decrease in avoidant coping from baseline to six months follow-up, it increased significantly from 6 to 21 months followup. It is possible that the women were initially more 
focused on the pregnancy and moving into child rearing which require marked changes in responsibility and lifestyle. This could result in a delayed psychological response to the diagnosis which could explain the increase in avoidant coping about six months after diagnosis (three months post-partum).

Initially, distraction was one of the frequently used avoidant coping strategies, which involves keeping busy with other activities (e.g. child rearing) to cope with a situation considered unchangeable (Eller et al., 2010; Skinner et al., 2003). After the first few months post-partum, the mother had more time to process the implications of the HIV diagnosis. While previous research showed a decrease in avoidant coping strategies over time (Olley, 2006; Olley et al., 2006), denial and emotional venting increased significantly from 12 to 21 months follow-up. This may be due to the gradual coming to terms with the reality of HIV and its social and health consequences. In addition, it was found that more women started on ART from 12 months follow-up onwards due to low CD4 counts. This suggests that some women's health may have deteriorated during that time. Previous research showed a direct link between deteriorating health and avoidant coping (Chida \& Vedhara, 2009). Consequently, the decrease in their health may also have contributed to the increase in avoidant coping.

Findings from the present study indicate that feelings of being out-of-control decreased significantly over time. Previous research (Pittiglio \& Hough, 2009; Reeves et al., 1999; Vervoort, Grypdonck, de Grauwe, Hoepelman, \& Borleffs, 2009) has found that women's feeling of being out-of-control decreased significantly as they gained access to health care. By promoting an internal locus of control in newly diagnosed HIV-positive women, health care professionals can assist newly diagnosed women to develop a greater sense of ownership regarding their health care.

Another notable finding of the present study was the significant decrease in self-blame from 12 months follow-up onwards. This finding is consistent with previous research (Myint \& Mash, 2008; Olley, 2006) and lends support to the notion that as time progresses HIV-positive people accept their status and hold less self-blaming attitudes.

The observation that various forms of avoidant coping were used differently over time, may indicate that avoidant coping is not a unified construct. The low reliability coefficient of this scale confirms this and may complicate the interpretation of the results. Changes in specific strategies can therefore give a more accurate perspective on women's coping over time. The repeated use of the same assessment tool may also influence the accuracy of the data.
The use of active and avoidant coping over time illustrates that coping is a continuously changing process that changes in response to the stressful environment (Lazarus \& Folkman, 1984). The research does not identify specific stages in coping, nor does it confirm the pattern of increasing active and decreasing avoidant coping (Olley, 2006; Reeves et al., 1999). This research sheds new light on how coping of women diagnosed during pregnancy evolves within the first two years after diagnosis and adds to our knowledge of coping patterns beyond six months after diagnosis. The findings, particularly the observation of a shift from inward to increased outward coping, the importance of initial distraction and that some forms of avoidant coping increased around six months after diagnosis (when the infant is three months old), may have important implications for counselling. Mental health professionals, who are aware of these changes over time, can assist women in developing appropriate coping strategies.

\section{Acknowledgements}

This study was funded by National Institute of Child Health and Human Development (NICHD) grant R24HD43558. We acknowledge the valuable contribution of the research team: R. Mkhondo, J. Tatane, M. Zondo, J. Ramodike, F. Nkomo, R. Kgoebane, M. Dikolometsa, P. Mabota, B. Moalosi, S. Sono and K. Lehobye.

\section{References}

Blaney, N. T., Fernandez, M. I., Ethier, K. A., Wilson, T. E., Walter, E., \& Koenig, L. J. (2004). Psychosocial and behavioural correlates of depression among HIVinfected pregnant women. AIDS Patient Care and STDs, 18(7), 405-415. doi:10.1089/1087291041518201

Carver, C. S. (1997). You want to measure coping but your protocol's too long: Consider the Brief COPE. International Journal of Behavioral Medicine, 4, 92100. doi:10.1207/s15327558ijbm0401_6

Chida, Y., \& Vedhara, K. (2009). Adverse psychosocial factors predict poorer prognosis in HIV disease: A meta-analytic review of prospective investigations. Brain, Behavior, and Immunity, 23, 434-445. doi:10. 1016/j.bbi.2009.01.013

Eller, L. S., Bunch, E. H., Wantland, D. J., Portillo, C. J., Reynolds, N. R., Nokes, K. M., \& Tsai, Y. F. (2010). Prevalence, correlates, and self-management of HIVrelated depressive symptoms. AIDS Care, 22(9), 11591170. doi:10.1080/09540121.2010.498860

Fleishman, J. A., Sherbourne, C. D., Cleary, P. D., Wu, A. W., Crystal, S., \& Hays, R. D. (2003). Patterns of coping among persons with HIV infection: Configurations, correlates and change. American Journal of Psychology, 32(1/2), 187-204. doi:10.1023/A:1025667 512009 
Griswold, G. A., Evans, S., Spielman, L., \& Fishman, B. (2005). Coping strategies of HIV patients with peripheral neuropathy. AIDS Care, 17(6), 711-720. doi:10. $1080 / 09540120412331336715$

Kubler-Ross, E. (1969). On death and dying. London: Tavistock.

Lazarus, R. S., \& Folkman, S. (1984). Stress, appraisal and coping. New York, NY: Springer.

Leiberich, P., Engeter, M., Olbrich, E., Rubbert, A., Schumacher, K., Brieger, M., \& Joraschky, P. (1997). Longitudinal development of distress, coping and quality of life in HIV-positive persons. Psychotherapy and Psychosomatics, 66, 237-247. doi:10.1159/000289141

Makin, J. D., Forsyth, B. W. C., Visser, M. J., Sikkema, K. J., Neufeld, S., \& Jeffery, B. (2008). Factors affecting disclosure in South African HIV-positive pregnant women. AIDS Patient Care and STDs, 22(11), 907916. doi:10.1089/apc.2007.0194

Myint, T., \& Mash, B. (2008). Coping strategies and social support after receiving HIV-positive results at a South African district hospital. South African Medical Journal, 98(4), 276-277. Retrieved from http://0-samj. org.za.innopac.up.ac.za/index.php/samj/article/view/ $95 / 871$

Olley, B. O. (2006). Psychological distress in the first year after diagnosis of HIV infection among women in South Africa. African Journal of AIDS Research, 5(3), 207-215. doi:10.2989/16085900609490381

Olley, B. O., Seedat, S., \& Stein, D. J. (2006). Persistence of psychiatric disorders in a cohort of HIV/AIDS patients in South Africa: A 6-month follow-up study. Journal of Psychosomatic Research, 61, 479-484. doi:10.1016/ j.jpsychores.2006.03.010
Pittiglio, L., \& Hough, E. (2009). Coping with HIV: Perspectives of mothers. Journal of the Association of Nurses in AIDS Care, 20(3), 184-192. doi:10.1016/ j.jana.2009.02.001

Reeves, P. M., Merriam, S. B., \& Courtenay, B. C. (1999). Adaptation to HIV infection: The development of coping strategies over time. Qualitative Health Research, 9(3), 344-361. doi:10.1177/1049732991291 21901

Sanders, L. B. (2008). Women's voices: The lived experience of pregnancy and motherhood after diagnosis. Journal of the Association of Nurses in AIDS Care, 19(1), 4757. doi:10.1016/j.jana.2007.10.002

Skinner, E. A., Edge, K., Altman, J., \& Sherwood, H. (2003). Searching for the structure of coping: A review and critique of category systems for classifying ways of coping. Psychological Bulletin, 129(2), 216-269. doi:10. 1037/0033-2909.129.2.216

Trevino, K. M., Pargament, K. I., Cotton, S., Leonard, A. C., Hahn, J., Caprini-Faigin, C. A., \& Tsevat, J. (2007). Religious coping and physiological, psychological, social, and spiritual outcomes in patients with HIV/AIDS: Cross-sectional and longitudinal findings. AIDS and Behavior, 14(2), 379-389. doi:10.1007/ s10461-007-9332-6

Vervoort, S. C. J. M., Grypdonck, M. H. F., de Grauwe, A., Hoepelman, A. I. M., \& Borleffs, J. C. C. (2009). Adherence to HAART: Processes explaining adherence behaviour in acceptors and non-acceptors. AIDS Care, 21(4), 431-438. doi:10.1080/0954012080 2290381 